\title{
Short communication: Odd-chain and branched-chain fatty acid concentrations in bovine colostrum and transition milk and their stability under heating and freezing treatments
}

\author{
Hangshu Xin, ${ }^{1,2}$ () Yang Xu, ${ }^{2}$ () Yanhong Chen, ${ }^{2}$ Guanqun Chen, ${ }^{2} \odot$ Michael A. Steele, ${ }^{3} \odot$ and Le Luo Guan ${ }^{2 *}$ () \\ ${ }^{1}$ College of Animal Science and Technology, Northeast Agricultural University, Harbin, 150030, China \\ ${ }^{2}$ Department of Agricultural, Food and Nutritional Science, University of Alberta, Edmonton, AB T6G 2P5, Canada \\ ${ }^{3}$ Department of Animal Biosciences, University of Guelph, Guelph, ON, N1G 2W1, Canada
}

\begin{abstract}
Although odd-chain fatty acids (OCFA) and branched-chain fatty acids (BCFA) are found in bovine milk and have some positive influences on human and animal health, their concentrations in bovine colostrum and transition milk have not been reported. In this study, we reported the OCFA and BCFA concentrations in colostrum and transition milk and their stability after heating or freezing treatments (or both), which are processes commonly applied in dairy calf management. Milk samples were collected from 12 Holstein dairy cows (6 primiparous and 6 multiparous) at the first milking (colostrum), fifth milking (transition milk), and ninth milking (mature milk) after calving, respectively, and were used for fatty acid analysis using gas chromatography. The sum concentration of OCFA and BCFA (termed OBCFA) was $134 \mathrm{mg} / 100 \mathrm{~g}$ of milk in the colostrum, which was $24 \%$ and $35 \%$ lower than that in the transition milk and mature milk, respectively. Among these fatty acids detected, C15:0 and C17:0 were the top 2 abundant fatty acids in all milk types, accounting for 20 to $25 \%$ and 21 to $24 \%$ of the total concentration of OBCFA, respectively. Additionally, anteiso-C17:0 was the most abundant BCFA, followed by iso-C17:0, anteiso-C15:0, iso-C16:0, iso-C15:0, iso-C18:0, and iso-C14:0 in 3 types of milk. Significant interactions between milk type and cow parity were observed for all OCFA and BCFA concentrations. The milk samples were also treated with heating (at $65^{\circ} \mathrm{C}$ for $60 \mathrm{~min}$ ), freezing (at $-20^{\circ} \mathrm{C}$ for $30 \mathrm{~d}$ ), and heating and freezing (at $65^{\circ} \mathrm{C}$ for $60 \mathrm{~min}$ and then at $-20^{\circ} \mathrm{C}$ for $30 \mathrm{~d}$ ), and milk OCFA and BCFA concentrations were similar between these treatments. In conclusion, the OBCFA concentration was lower in colostrum,
\end{abstract}

Received May 31, 2020.

Accepted July 27, 2020.

*Corresponding author: lguan@ualberta.ca compared with transition and mature milks, and it remained stable after heating and freezing treatments. Key words: odd-chain and branched-chain fatty acids, colostrum, transition milk, stability

\section{Short Communication}

Odd-chain fatty acids (OCFA) are a group of straight-chain fatty acids having an odd number of carbon atoms, whereas branched-chain fatty acids (BCFA) are isomer fatty acids with a methyl branch on the penultimate or ultimate carbon. The odd- and branched-chain fatty acids include tetradecanoic acid (iso-C14:0), pentadecanoic acid (C15:0, iso-C15:0 and anteiso-C15:0), hexadecanoic acid (iso-C16:0), heptadecanoic acid (C17:0, iso-C17:0 and anteiso-C17:0), and stearic acid (iso-C18:0) (Vlaeminck et al., 2006; Ran-Ressler et al., 2014). Recently, OCFA and BCFA (termed OBCFA) have gained significant attention as bioactives, especially for their biological impact on the gut health of mammals. For example, C17:0, the most abundant OCFA in the colon lumen, has been reported to promote gastrointestinal movement in rats and concentration of $\mathrm{C} 17: 0$ had a positive association with abundances of bacterial genera Prevotella and Lactobacillus (Zhao et al., 2018). These 2 bacteria displayed significantly higher relative abundances in healthy rodents than those with gut disorder (Liu et al., 2018a; Wang et al., 2019). As for BCFA, Ran-Ressler et al. (2008) identified that they were constituents in newborn infants' guts and speculated that these BCFA might play a role in gut development. In support of this hypothesis, the same researchers found that replacing $20 \%$ of milk fat with BCFA dramatically reduced necrotizing enterocolitis incidence in neonatal rats (Ran-Ressler et al., 2011). Additionally, our preliminary study illustrated remarkably different BCFA profiles in feces between diarrheic and healthy dairy calves, and some BCFA (e.g., anteiso-C15:0, iso-C16:0, iso-C17:0, isoC18:0, and total even-chain BCFA) might potentially 
be used as classifiers or predictors of gut health status in neonatal calves (H. Xin, T. Ma, Y. Xu, G, Chen, Y. Chen, C. Villot, D. L. Renaud, M. A. Steele, and L. L. Guan; Northeast Agricultural University, Harbin, China; University of Alberta, Edmonton, Canada; Chinese Academy of Agricultural Science, Beijing, China; University of Guelph, Guelph, Canada; unpublished data). These results suggest that OBCFA could benefit human and animal health through potential effects on gut functions.

Bovine colostrum, the first mammary secretion at the onset of lactation, is rich in bioactive compounds and immunoregulatory factors that are crucial to newborn calf survival and health (Fahey et al., 2020; Fischer-Tlustos et al., 2020). Some fatty acids, as part of bioactives, have been reported to have antimicrobial functions (Hristov et al., 2004) and be essential for immune system development and activation in calves (Hill et al., 2011). However, research on colostrum fatty acids has been primarily focused on UFA, such as transisomers (e.g., trans 18:1, 18:2, and 18:3 isomers) and conjugated linoleic acid (Leiber et al., 2011; Contarini et al., 2014; O'Callaghan et al., 2020). Compared with colostrum, the subsequent 2 to 6 milk secretions (referred to as transition milk) exhibit remarkable changes in bioactive amounts (Blum and Hammon, 2000). To date, there are considerable publications reporting the presence of OCFA and BCFA in milk (Vlaeminck et al., 2006; Rodríguez-Alcalá et al., 2014; Bainbridge et al., 2016), but they have not been reported in bovine colostrum and transition milk.

In the dairy industry, colostrum and transition milk are usually pasteurized using heat treatment with low temperature (usually at $60-65^{\circ} \mathrm{C}$ for $30-60 \mathrm{~min}$ ) to eliminate potential pathogenic microorganisms (Godden et al., 2006) and then stored frozen for further use. In addition, bovine raw milk is also pasteurized (e.g., $63^{\circ} \mathrm{C}$ for $30 \mathrm{~min}$ ) before human consumption, which is an effective way to kill harmful bacteria that can cause disease. It has been known that milk lipid is stable, especially SFA, which do not easily react with most chemicals, even under different heating conditions (Rodríguez-Alcalá et al., 2014). It has been reported that pasteurization could significantly reduce relative abundance of Pseudomonas spp. (from 26\% to 4\%; Quigley et al., 2013), one of microorganisms causing raw milk spoilage (Ternström et al., 1993) and containing OCFA and BCFA in their cell membranes (Kaneda, 1991; Chao et al., 2010), suggesting that such a process may alter OBCFA concentrations in the milk. In addition, formation of ice crystals intercellularly during freezing storage could damage bacterial cell membranes, which would cause lipid loss (Ray and Speck, 1973). Moreover, freezing can also destroy milk fat globules and lead to reduced milk quality, as previously reviewed by Muir (1984). These results suggest that milk OCFA and BCFA concentrations could change after heating or freezing treatments (or both). Therefore, the aims of the present study were to (1) characterize the OCFA and BCFA concentrations in bovine colostrum, transition milk, and mature milk, and (2) investigate whether heating or freezing treatments (or both) affect the OCFA and BCFA concentrations in these 3 types of milk.

Three types of milk samples used in this study were collected from 12 healthy Holstein dairy cows (6 primiparous cows and 6 multiparous cows) co-housed with the same ration management (Table 1) at the Dairy Research and Technology Centre, University of Alberta. After parturition, milk samples (50 mL/sample) were collected from each cow as (1) colostrum (the first milking), (2) transition milk (the fifth milking), and (3) mature milk (the ninth milking). All samples were separated into 4-aliquot sets and were randomly assigned to 1 of 4 treatments: (1) raw, (2) heating treatment: incubated at $65^{\circ} \mathrm{C}$ in a water bath (Grant Optima T100, Cambridge Ltd., Cambridge, UK) for $60 \mathrm{~min}$, (3) freezing treatment: frozen for $30 \mathrm{~d}$ at $-20^{\circ} \mathrm{C}$, and (4) heating and freezing treatment: incubated at $65^{\circ} \mathrm{C}$ in a water bath for $60 \mathrm{~min}$ and then frozen at $-20^{\circ} \mathrm{C}$ for 30 d. The OCFA and BCFA analyses were performed on the same day of sample collection for the raw and heattreated samples, and on d 30 for the frozen and heated and frozen samples. Twenty microliters of $50 \mathrm{mg} / \mathrm{mL}$ nonadecanoic acid (C19:0; Larodan Fine Chemicals, Malmo, Sweden) was added as an internal standard to each nylon-cap glass tube following being dried under $\mathrm{N}_{2}$. Then, around $0.2 \mathrm{~g}$ of milk samples was added into the same glass tube for lipid extraction according to the procedures described by Erickson and Dunkley (1964). Subsequently, the extracted milk lipid was methylated with $3 \mathrm{M}$ methanolic $\mathrm{HCl}$ and incubated at $80^{\circ} \mathrm{C}$ for 1 $\mathrm{h}$ (Raes et al., 2001). Then the mixture was neutralized with $0.9 \% \mathrm{NaCl}$ and re-extracted with hexane. Finally, the upper organic phase was collected, dried under $\mathrm{N}_{2}$, and reconstituted in $1 \mathrm{~mL}$ of isooctane for analysis on an Agilent 6890N Gas Chromatograph (Agilent Technologies, Santa Clara, CA). The temperature procedure for the GC oven was set according to Dingess et al. (2017). Individual fatty acid was identified according to peak and retention time of standards including iso$\mathrm{C} 14: 0$, iso-C15:0, anteiso-C15:0, C15:0, iso-C16:0, iso$\mathrm{C} 17: 0$, anteiso-C17:0, C17:0, and iso-C18:0 (Larodan Fine Chemicals, Malmo, Sweden). Fatty acid quantification was double confirmed on an Agilent 6890N Gas Chromatograph equipped with a 5975 inert XL Mass Selective Detector (Agilent Technologies). The data were analyzed using PROC MIXED model in SAS 
Table 1. Ingredient and chemical compositions of the prepartum and postpartum diets

\begin{tabular}{lc}
\hline Item & Value \\
\hline Prepartum & \\
Ingredient, TMR, \% & \\
Barley straw & 21.75 \\
Barley silage & 40.92 \\
Bypass soy & 5.23 \\
Barley grain & 2.61 \\
Corn grain & 5.97 \\
Canola meal & 6.45 \\
Beet pulp & 5.82 \\
Corn gluten meal & 0.90 \\
Corn distillers & 2.09 \\
Soybean hulls & 3.73 \\
Yeast & 0.03 \\
Premix & 4.5 \\
Chemical composition, \% DM & \\
CP & 14.67 \\
Ether extract & 3.24 \\
NDF & 43.54 \\
ADF & 28.12 \\
peNDF & 31.92 \\
Starch & 16.39 \\
Postpartum & \\
Ingredient, TMR, \% & \\
Alfalfa & 7.15 \\
Barley silage & 42.81 \\
Bypass soy & 7.41 \\
Barley grain & 13.72 \\
Corn grain & 13.86 \\
Canola meal & 10.73 \\
Beet pulp & 1.11 \\
Corn gluten meal & 0.74 \\
Premix & 2.5 \\
Chemical composition, \% DM & \\
CP & 17.39 \\
Ether extract & 33.91 \\
NDF & 22.6 \\
ADF & 21.7 \\
peNDF & 24.1 \\
Starch & \\
\hline The premx contained & \\
\hline
\end{tabular}

${ }^{1}$ The premix contained $0.26 \%$ dry cow plus PMX, $1.49 \%$ limestone (40\%), $0.15 \% \mathrm{MgO}$ (55\%), $1.49 \%$ Animate, $0.30 \% \mathrm{MgSO}_{4}(10 \%)$, $0.34 \% \mathrm{CaHPO}_{4}, 0.01 \%$ monensin sodium $(200 \mathrm{mg} / \mathrm{kg}), 0.07 \%$ vitamin $\mathrm{E}(50,000 \mathrm{IU} / \mathrm{kg})$, and $0.37 \%$ choline. This product was obtained from Nutrisource, Strathmore, AB, Canada.

${ }^{2}$ peNDF $=$ physically effective NDF.

${ }^{3}$ The premix contained $0.82 \%$ limestone $(40 \%), 0.17 \%$ dairy plus PMX, $0.34 \% 0.19 \% \mathrm{MgO}(55 \%), 0.41 \% \mathrm{NaHCO}_{3}, 0.45 \%$ calcium magnesium mixture, $0.34 \%$ red salt, $0.02 \%$ yeast, and $0.09 \%$ methionine. This product was obtained from Nutrisource.

(version 9.4, SAS Institute Inc., Cary, NC). The model included the fixed effects of milk types (colostrum, transition milk, and mature milk), parity (primiparous and multiparous), and treatments (raw, heated, frozen, and heated and frozen), interaction effects (milk type $\times$ parity and milk type $\times$ treatment), and random effect of dairy cows. Statistical significances were declared at $P<0.05$.

In total, 9 OBCFA were identified in 3 types of milk (Table 2), including 2 OCFA (C15:0 and C17:0), 5 iso-BCFA (iso-C14:0, iso-C15:0, iso-C16:0, iso-C17:0, and iso-C18:0) and 2 anteiso-BCFA (anteiso-C15:0 and anteiso-C17:0). The concentrations of total OBCFA ranged from 89 to $268 \mathrm{mg} / 100 \mathrm{~g}$ of milk in all milk samples which are within the ranges summarized by Vlaeminck et al. (2006). Among them, OCFA of C15:0 and C17:0 were the top 2 abundant fatty acids, accounting for 20 to $25 \%$ and 21 to $24 \%$ of the total concentration of OBCFA, respectively. These are consistent with their abundances in the milk of Holstein cows taken from d 5 after parturition (Bainbridge et al., 2016) and in the milk samples collected over 40 wk of lactation (Craninx et al., 2008), as previously reported. In the present study, total OCFA concentrations ranged from 44.4 to $120.9 \mathrm{mg} / 100 \mathrm{~g}$ of milk, accounting for 45 to $50 \%$ of total concentration of OBCFA in milk samples. The OCFA are mainly formed by repeated condensation of malonyl-CoA with propionyl-CoA as the precursor (Fulco, 1983). In addition to that, Emmanuel (1978) found that OCFA could also be produced by rumen bacteria in a pure culture system through $\alpha$-oxidation from even-chain fatty acids (e.g., C16:0 or C18:0) which are originated from acetate or butyrate (Kaneda, 1991). Therefore, the proportion of OCFA observed in this study could probably reflect the availability of these fatty acid precursors in ruminants. On the other hand, total concentrations of BCFA ranged from 69.2 to $147.6 \mathrm{mg} / 100 \mathrm{~g}$ of milk in the milk samples. Among them, anteiso-C17:0 was the most predominant fatty acid in all milk samples, followed by iso-C17:0, anteisoC15:0, iso-C16:0, iso-C15:0, iso-C18:0, and iso-C14:0. Meanwhile, the concentrations of total iso-BCFA and total anteiso-BCFA ranged from 25 to $79 \mathrm{mg} / 100 \mathrm{~g}$ of milk and 20 to $69 \mathrm{mg} / 100 \mathrm{~g}$ of milk, respectively, in different milk samples. The amount of total iso-BCFA and total anteiso-BCFA in mature milk obtained from primiparous cows in our study is greater than the findings of Bainbridge et al. (2016) who reported the total concentrations of iso- and anteiso-BCFA were 38 and 30 $\mathrm{mg} / 100 \mathrm{~g}$ of milk in the milk obtained from primiparous Holstein dairy cows $5 \mathrm{~d}$ after calving. Generally, BCFA are produced by short branched-chain fatty acids which are related to branched-chain fatty acids (e.g., valine, leucine, and isoleucine; Kaneda, 1991). Specifically, the iso-BCFA (e.g., iso-C14:0 and iso-C16:0) are originated from isobutyrate and isovalerate (e.g., iso-C15:0 and iso-C17:0), whereas anteiso-BCFA (e.g., anteiso-C15:0 and anteiso-C17:0) originate from 2-methybutyrate in ruminants (Vlaeminck et al., 2006). The generation of these short BCFA is also highly associated with the breed (Bainbridge et al., 2016), dietary strategy, ruminal environment, and physiological conditions of cows (Liu et al., 2018b; Roman-Garcia, 2019). The varied management, diets, and sampling time might partly explain the inconsistent concentrations of iso- and 
anteiso-BCFA between these 2 studies. To date, limited information is available regarding abundance of isoand anteiso-BCFA in colostrum and transition milk. Thus, future studies are needed to determine whether cow nutrition, breed, or other factors affect their concentrations in these 2 types of milk.

All individual OCFA and BCFA concentrations were significantly affected by the interactions of milk type and cow parity $(P<0.05$; Table 2$)$. In general, for each fatty acid, the highest level was found in the mature milk from primiparous cows, whereas the colostrum milk from multiparous cows had the lowest concentrations $(P<0.05)$. Meanwhile, the concentrations of OCFA and BCFA in colostrum obtained from either primiparous or multiparous cows were lower than those in transition and mature milks. Consequently, similar tendencies were observed in the concentrations of total OCFA, total BCFA, total iso-BCFA, total anteisoBCFA, as well as total OBCFA in all milk samples. Similarly, a previous study has reported that the sum concentrations of C15:0 and C17:0 were increased from 5 to 275 lactation days in both Holstein and Jersey cows (Bainbridge et al., 2016). In addition, Leiber et al. (2011) concluded that total BCFA concentration in milk linearly increased from $1.20 \%$ to $1.67 \%$ (\% of total fatty acids) during the first $40 \mathrm{~d}$ of early lactation. It is known that OCFA and BCFA are particularly prominent in ruminant products, as they are mainly synthesized by microorganisms in the rumen (Kaneda, 1991). After calving, the cows usually have a strong decline in DMI, especially during the first few hours postpartum (Grummer, 1995), which could lead to the lower availability of substrates for fatty acid synthesis. This may in part explain the decrease in sum production of OCFA and BCFA in colostrum. In addition, we measured fatty acid concentrations in a commercial milk replacer (MR) and found there was only 0.70 and $0.61 \mathrm{mg} / \mathrm{g}$ of OCFA and BCFA, respectively, in this MR product (Supplemental Table S1; https://doi .org/10.3168/jds.2020-18994). Given MR is formulated with water $(\mathrm{MR}$ : water $=1: 7$; wt $/ \mathrm{wt})$ when feeding the calves, the total OBCFA content in $100 \mathrm{~g}$ of MR liquid is estimated to be $16.4 \mathrm{mg}$, which is only $9.8 \%$ and $8.2 \%$ of that found in $100 \mathrm{~g}$ of bovine transition milk and mature milk, respectively. This suggests that the MR feeding may not have the health benefit of bovine milk due to low contents of OCFA and BCFA and future MR manufacturing should consider OCFA and BCFA as part of its nutritional component. In addition, our results showed that individual milk OCFA and BCFA concentrations in primiparous cows were 1.0 to 2.6 times higher than those of multiparous cows. In a previous study, Craninx et al. (2008) observed significantly higher levels of OCFA and BCFA (e.g.,

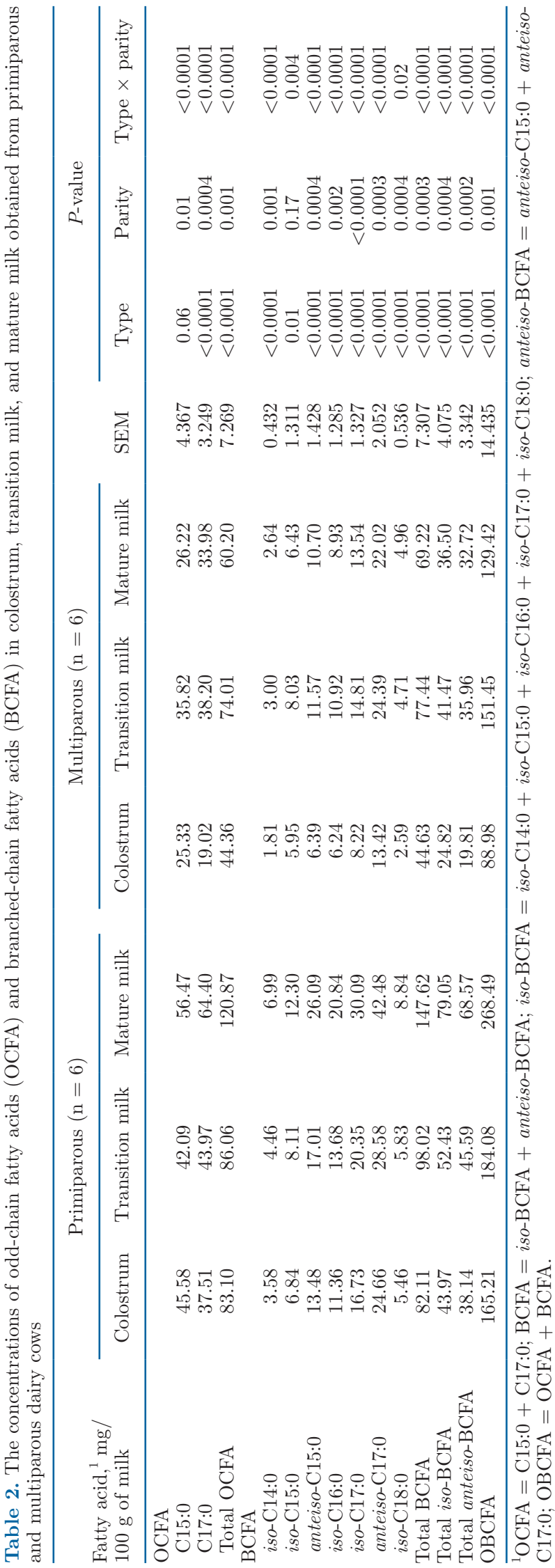

Journal of Dairy Science Vol. 103 No. 12, 2020 
Table 3. The odd-chain fatty acid (OCFA) and branched-chain fatty acid (BCFA) concentrations in raw and treated milk samples

\begin{tabular}{|c|c|c|c|c|c|c|}
\hline $\begin{array}{l}\text { Fatty acid, }{ }^{1} \mathrm{mg} / \\
100 \mathrm{~g} \text { of milk }\end{array}$ & Raw & Heated & Frozen & $\begin{array}{l}\text { Heated } \\
\text { and frozen }\end{array}$ & SEM & $P$-value \\
\hline \multicolumn{7}{|l|}{ OCFA } \\
\hline C15:0 & 38.84 & 36.56 & 40.34 & 38.42 & 4.404 & 0.693 \\
\hline C17:0 & 39.91 & 36.59 & 41.14 & 39.42 & 4.091 & 0.686 \\
\hline Total OCFA & 78.75 & 73.15 & 81.51 & 77.85 & 8.251 & 0.668 \\
\hline \multicolumn{7}{|l|}{ BCFA } \\
\hline iso-C14:0 & 3.87 & 3.55 & 3.93 & 3.65 & 0.516 & 0.707 \\
\hline iso-C15:0 & 7.18 & 6.82 & 8.93 & 8.60 & 1.084 & 0.166 \\
\hline anteiso-C15:0 & 14.25 & 13.38 & 14.94 & 14.17 & 1.888 & 0.748 \\
\hline iso-C16:0 & 12.04 & 11.05 & 12.76 & 12.01 & 1.463 & 0.566 \\
\hline iso-C17:0 & 17.52 & 16.33 & 17.83 & 17.19 & 2.025 & 0.826 \\
\hline anteiso-C17:0 & 25.99 & 23.99 & 27.19 & 26.05 & 2.658 & 0.632 \\
\hline iso-C18:0 & 6.00 & 5.07 & 5.33 & 5.12 & 0.622 & 0.429 \\
\hline Total BCFA & 86.87 & 80.20 & 90.94 & 86.79 & 9.638 & 0.631 \\
\hline Total iso-BCFA & 46.62 & 42.83 & 48.80 & 46.57 & 5.203 & 0.608 \\
\hline Total anteiso-BCFA & 40.24 & 39.70 & 40.36 & 40.22 & 4.364 & 0.998 \\
\hline OBCFA & 165.61 & 153.35 & 172.46 & 164.63 & 17.775 & 0.642 \\
\hline
\end{tabular}

iso-C14:0, iso-C15:0, iso-C16:0, and C17:0) in milk taken from cows with parity $\leq 2$, compared with milk from older cows, which is in agreement with our findings. It is known that multiparous cows usually have higher milk production potential (Nielsen et al., 2003), and higher incidence of metabolic diseases with lipid metabolism disorder (e.g., ketosis) compared with primiparous cows (Markusfeld, 1987; Suthar et al., 2013). These suggest that the physiological and metabolic differences between multiparous and primiparous may affect OCFA and BCFA concentrations in milk, which warrants further investigation in the future.

The OCFA and BCFA concentrations in colostrum, transition milk, and mature milk did not change after heated, frozen, or heated and frozen treatments (Table 3). Similar to our results, Rodríguez-Alcalá et al. (2014) did not observe alternations in OCFA and BCFA concentrations in 2 different batches of milk samples after heating with low $\left(72^{\circ} \mathrm{C}, 30 \mathrm{~s}\right)$ and high temperatures $\left(135^{\circ} \mathrm{C}, 30 \mathrm{~s}\right.$ or $\left.150^{\circ} \mathrm{C}, 5 \mathrm{~min}\right)$. It is well known that OCFA and BCFA are SFA, which have single bonds through all carbon chains. Therefore, they are highly stable and not readily broken in various environments. The freezing treatment in our study also did not compromise OCFA and BCFA concentrations in bovine milk, which is consistent with observations of unaltered fatty acid concentrations in sheep milk samples frozen for 1 to 6 mo (Zhang et al., 2006). The stability of OBCFA concentrations in heated, frozen, and heated and frozen milks suggest that these processes would not affect their potential bioactivities.

In summary, OCFA and BCFA concentrations were affected by milk type, parity, as well as their interaction. The total concentration of OCFA and BCFA was lower in colostrum, compared with transition milk and mature milk samples. In addition, these fatty acid concentrations did not change after heating, freezing, or heating and freezing treatments, suggesting the commonly used pasteurization and storage practices on farm do not affect the stability of OCFA and BCFA. The identification of OCFA and BCFA in different milk types suggest that these fatty acids could play a role in calf and human infant gut health in addition to other known bioactives. In addition, the identified OCFA and BCFA in milk highlight the importance of formulating MR or starter with supplementation of these fatty acids that are needed to provide better nutritional values to dairy calves.

\section{ACKNOWLEDGMENTS}

This study was supported by the Natural Sciences and Engineering Research Council of Canada Discovery grants to G.C. and L.L.G. Westgen, BC Dairy Association, Alberta Milk, SaskMilk, and Dairy Farmers of Manitoba and by the National Natural Science Foundation of China (grant no. 31702135) and Chinese Scholarship Council (CSC). We are grateful to C. Felton (Dairy Research and Technology Centre, Edmonton, Canada) for her assistance with milk sample collections. The authors have no conflicts of interest to declare.

\section{REFERENCES}

Bainbridge, M. L., L. M. Cersosimo, A. D. G. Wright, and J. Kraft. 2016. Content and composition of branched-chain fatty acids in bovine milk are affected by lactation stage and breed of dairy cow. PLoS One 11:e0150386. 
Blum, J. W., and H. Hammon. 2000. Colostrum effects on the gastrointestinal tract, and on nutritional, endocrine and metabolic parameters in neonatal calves. Livest. Prod. Sci. 66:151-159. https: //doi.org/10.1016/S0301-6226(00)00222-0.

Chao, J., G. M. Wolfaardt, and M. T. Arts. 2010. Characterization of Pseudomonas aeruginosa fatty acid profiles in biofilms and batch planktonic cultures. Can. J. Microbiol. 56:1028-1039. https://doi .org/10.1139/W10-093.

Contarini, G., M. Povolo, V. Pelizzola, L. Monti, A. Bruni, L. Passolungo, F. Abeni, and L. Degano. 2014. Bovine colostrum: Changes in lipid constituents in the first 5 days after parturition. J. Dairy Sci. 97:5065-5072. https://doi.org/10.3168/jds.2013-7517.

Craninx, M., A. Steen, H. Van Laar, T. Van Nespen, J. Martin-Tereso, B. De Baets, and V. Fievez. 2008. Effect of lactation stage on the odd-and branched-chain milk fatty acids of dairy cattle under grazing and indoor conditions. J. Dairy Sci. 91:2662-2677. https:/ /doi.org/10.3168/jds.2007-0656.

Dingess, K. A., C. J. Valentine, N. J. Ollberding, B. S. Davidson, J. G. Woo, S. Summer, Y. M. Peng, M. L. Guerrero, G. M. RuizPalacios, R. R. Ran-Ressler, R. J. McMahon, J. T. Brenna, and A. L. Morrow. 2017. Branched-chain fatty acid composition of human milk and the impact of maternal diet: The Global Exploration of Human Milk (GEHM) study. Am. J. Clin. Nutr. 105:177-184. https://doi.org/10.3945/ajcn.116.132464.

Emmanuel, B. 1978. The relative contribution of propionate, and longchain even-numbered fatty acids to the production of long-chain odd-numbered fatty acids in rumen bacteria. Biochim. Biophys. Acta 528:239-246. https://doi.org/10.1016/0005-2760(78)90198-4.

Erickson, D. R., and W. L. Dunkley. 1964. Spectrophotometric determination of tocopherol in milk and milk lipids. Anal. Chem. 36:1055-1058. https://doi.org/10.1021/ac60212a029.

Fahey, M. J., A. J. Fischer, M. A. Steele, and S. L. Greenwood. 2020. Characterization of the colostrum and transition milk proteomes from primiparous and multiparous Holstein dairy cows. J. Dairy Sci. 103:1993-2005. https://doi.org/10.3168/jds.2019-17094.

Fischer-Tlustos, A. J., K. Hertogs, J. K. van Niekerk, M. Nagorske, D. M. Haines, and M. A. Steele. 2020. Oligosaccharide concentrations in colostrum, transition milk, and mature milk of primi- and multiparous Holstein cows during the first week of lactation. J. Dairy Sci. 103:3683-3695. https://doi.org/10.3168/jds.2019-17357.

Fulco, A. J. 1983. Fatty acid metabolism in bacteria. Prog. Lipid Res. 22:133-160. https://doi.org/10.1016/0163-7827(83)90005-X.

Godden, S., S. McMartin, J. Feirtag, J. Stabel, R. Bey, S. Goyal, L. Metzger, J. Fetrow, S. Wells, and H. Chester-Jones. 2006. Heattreatment of bovine colostrum. II: Effects of heating duration on pathogen viability and immunoglobulin G. J. Dairy Sci. 89:34763483. https://doi.org/10.3168/jds.S0022-0302(06)72386-4.

Grummer, R. R. 1995. Impact of changes in organic nutrient metabolism on feeding the transition dairy cow. J. Anim. Sci. 73:28202833. https://doi.org/10.2527/1995.7392820x.

Hill, T. M., M. J. VandeHaar, L. M. Sordillo, D. R. Catherman, H. G. Bateman II, and R. L. Schlotterbeck. 2011. Fatty acid intake alters growth and immunity in milk-fed calves. J. Dairy Sci. 94:39363948. https://doi.org/10.3168/jds.2010-3935.

Hristov, A. N., M. Ivan, and T. A. McAllister. 2004. In vitro effects of individual fatty acids on protozoal numbers and on fermentation products in ruminal fluid from cattle fed a high concentrate, barley-based diet. J. Anim. Sci. 82:2693-2704. https://doi.org/10 $.2527 / 2004.8292693 x$

Kaneda, T. 1991. Iso- and anteiso-fatty acids in bacteria: Biosynthesis, function, and taxonomic significance. Microbiol. Rev. 55:288-302. https://doi.org/10.1128/MMBR.55.2.288-302.1991.

Leiber, F., R. Hochstrasser, H.-R. Wettstein, and M. Kreuzer. 2011. Feeding transition cows with oilseeds: Effects on fatty acid composition of adipose tissue, colostrum and milk. Livest. Sci. 138:1-12. https://doi.org/10.1016/j.livsci.2010.11.016.

Liu, J., R. Chang, X. Zhang, Z. Wang, J. Wen, and T. Zhou. 2018a. Non-isoflavones diet incurred metabolic modifications induced by constipation in rats via targeting gut microbiota. Front. Microbiol. 9:3002. https://doi.org/10.3389/fmicb.2018.03002.
Liu, Q., C. Wang, G. Guo, W. J. Huo, S. L. Zhang, C. X. Pei, Y. L. Zhang, and H. Wang. 2018b. Effects of branched-chain volatile fatty acids on lactation performance and mRNA expression of genes related to fatty acid synthesis in mammary gland of dairy cows. Animal 12:2071-2079. https://doi.org/10.1017/ S1751731118000113.

Markusfeld, O. 1987. Periparturient traits in seven high dairy herds. Incidence rates, association with parity, and interrelationships among traits. J. Dairy Sci. 70:158-166. https://doi.org/10.3168/ jds.S0022-0302(87)79990-1.

Muir, D. D. 1984. Reviews of the progress of dairy science: Frozen concentrated milk. J. Dairy Res. 51:649-664. https://doi.org/10 .1017/S0022029900032982.

Nielsen, H., N. C. Friggens, P. Løvendahl, J. Jensen, and K. L. Ingvartsen. 2003. Influence of breed, parity, and stage of lactation on lactational performance and relationship between body fatness and live weight. Livest. Prod. Sci. 79:119-133. https://doi.org/10 .1016/S0301-6226(02)00146-X.

O'Callaghan, T. F., M. O'Donovan, J. P. Murphy, K. Sugrue, D. Mannion, W. P. McCarthy, M. Timlin, K. N. Kilcawley, R. M. Hickey, and J. T. Tobin. 2020. Evolution of the bovine milk fatty acid profile-From colostrum to milk five days post parturition. Int. Dairy J. 104:104655. https://doi.org/10.1016/j.idairyj.2020.104655.

Quigley, L., R. McCarthy, O. O'Sullivan, T. P. Beresford, G. F. Fitzgerald, R. P. Ross, C. Stanton, and P. D. Cotter. 2013. The microbial content of raw and pasteurized cow milk as determined by molecular approaches. J. Dairy Sci. 96:4928-4937. https://doi .org/10.3168/jds.2013-6688.

Raes, K., S. De Smet, and D. Demeyer. 2001. Effect of double muscling in Belgian Blue young bulls on the intramuscular fatty acid composition with emphasis on conjugated linoleic acid and polyunsaturated fatty acids. Anim. Sci. 73:253-260. https://doi.org/10 $.1017 /$ S1357729800058227.

Ran-Ressler, R. R., S. Bae, P. Lawrence, D. H. Wang, and J. T. Brenna. 2014. Branched-chain fatty acid content of foods and estimated intake in the USA. Br. J. Nutr. 112:565-572. https://doi.org/10 $.1017 / \mathrm{S} 0007114514001081$

Ran-Ressler, R. R., S. Devapatla, P. Lawrence, and J. T. Brenna. 2008. Branched chain fatty acids are constituents of the normal healthy newborn gastrointestinal tract. Pediatr. Res. 64:605-609. https://doi.org/10.1203/PDR.0b013e318184d2e6.

Ran-Ressler, R. R., L. Khailova, K. M. Arganbright, C. K. AdkinsRieck, Z. E. Jouni, O. Koren, R. E. Ley, J. T. Brenna, and B. Dvorak. 2011. Branched chain fatty acids reduce the incidence of necrotizing enterocolitis and alter gastrointestinal microbial ecology in a neonatal rat model. PLoS One 6:e29032. https://doi.org/ 10.1371/journal.pone.0029032.

Ray, B., and M. L. Speck. 1973. Freeze-injury in bacteria. CRC Crit. Rev. Clin. Lab. Sci. 4:161-213. https://doi.org/10.3109/ 10408367309151556.

Rodríguez-Alcalá, L. M., L. Alonso, and J. Fontecha. 2014. Stability of fatty acid composition after thermal, high pressure, and microwave processing of cow milk as affected by polyunsaturated fatty acid concentration. J. Dairy Sci. 97:7307-7315. https://doi.org/10 $.3168 /$ jds.2013-7849.

Roman-Garcia, Y. 2019. Assessing dietary conditions influencing the requirements by rumen bacteria for branched chain volatile fatty acids. PhD Diss. The Ohio State University, Columbus.

Suthar, V. S., J. Canelas-Raposo, A. Deniz, and W. Heuwieser. 2013. Prevalence of subclinical ketosis and relationships with postpartum diseases in European dairy cows. J. Dairy Sci. 96:2925-2938. https://doi.org/10.3168/jds.2012-6035.

Ternström, A., A. M. Lindberg, and G. Molin. 1993. Classification of the spoilage flora of raw and pasteurized bovine-milk, with special reference to Pseudomonas and Bacillus. J. Appl. Bacteriol. 75:2534. https://doi.org/10.1111/j.1365-2672.1993.tb03403.x.

Vlaeminck, B., V. Fievez, A. R. J. Cabrita, A. J. M. Fonseca, and R. J. Dewhurst. 2006. Factors affecting odd-and branched-chain fatty acids in milk: A review. Anim. Feed Sci. Technol. 131:389-417. https://doi.org/10.1016/j.anifeedsci.2006.06.017. 
Wang, L., C. Chen, S. Cui, Y. Lee, G. Wang, J. Zhao, H. Zhang, and W. Chen. 2019. Adhesive Bifidobacterium induced changes in cecal microbiome alleviated constipation in mice. Front. Microbiol. 10:1721. https://doi.org/10.3389/fmicb.2019.01721.

Zhang, R. H., A. F. Mustafa, K. F. Ng-Kwai-Hang, and X. Zhao. 2006. Effects of freezing on composition and fatty acid profiles of sheep milk and cheese. Small Rumin. Res. 64:203-210. https://doi.org/ 10.1016/j.smallrumres.2005.04.025.

Zhao, L., Y. Huang, L. Lu, W. Yang, T. Huang, Z. Lin, C. Lin, H. Kwan, H. L. X. Wong, Y. Chen, S. Sun, X. Xie, X. Fang, H. Yang, J. Wang, L. Zhu, and Z. Bian. 2018. Saturated long-chain fatty acid-producing bacteria contribute to enhanced colonic motility in rats. Microbiome 6:107. https://doi.org/10.1186/s40168-018-0492 -6 .

\section{ORCIDS}

Hangshu Xin @ https://orcid.org/0000-0003-4180-2272

Yang Xu (ㄱ https://orcid.org/0000-0001-7587-2194

Guanqun Chen () https://orcid.org/0000-0001-5790-3903

Michael A. Steele (ㄴ) https://orcid.org/0000-0001-6941-6205

Le Luo Guan @ https://orcid.org/0000-0002-8420-4371 